\title{
Prizes (at last) for immunology
}

\section{This week's Nobel prize comes less than 10 years after monoclonal antibodies, already produced commercially as diagnostic reagents. But in that decade, immunology has been transformed.}

SOME Nobel prizes are inevitable, the only question being when the nomination will rise to the top of the pile. This year's prize for César Milstein must have been close to the top for at least three years. Nor does it come as any great surprise that Georges Kohler is the second of the three winners of this year's prize for Physiology and Medicine, for he and Milstein jointly discovered the principle of producing monoclonal antibodies. Less predictable is the third winner, Niels Jerne. But to immunologists, Jerne is the great man of influential ideas.

Köhler and Milstein published their paper on "Continuous cultures of fused cells secreting antibody of predefined specificity" in August 1975 (Nature 256, 495). It described how the fusion of a single lymphocyte-secreting antibody with a single bone marrow tumour (myeloma) cell resulted in a hybrid cell with the antibodyproducing capacity of the lymphocyte and the immortality of the malignant cell. Their antibody-producing cells came from the spleens of mice immunized with red blood cells from sheep, so that the fused cell lines (hybridomas) each secreted an antibody directed against the sheep cells. Köhler and Milstein emphasized that they could not tell whether similar results would be obtained with other antigens but, obviously believing they could, finished their paper by saying: "It is possible to hybridize antibody-producing cells from different origins. Such cells can be grown in vitro in massive cultures to provide specific antibody. Such cultures could be valuable for medical and industrial use."

They were right. Specific antibodies, now known as monoclonal antibodies, are an essential tool of much biomedical research and are of great commercial and medical value. The therapeutic use of monoclonal antibodies is still at an early stage, but they are already invaluable aids to diagnosis and screening. A good example is in blood grouping, where hybridomas established by Milstein are now the basis for the production of monoclonal antibodies on a sufficient scale to replace human sera in ABO blood typing in the United Kingdom.

César Milstein was born in Argentina in 1927 , and was on the staff of the Instituto Nacional de Microbiologica in Buenos Aires until 1963, taking time out to obtain a $\mathrm{PhD}$ at Cambridge in 1960 as a British Council Fellow. In 1963, he left Argentina to join the staff of the Medical Research Council Laboratory of Molecular Biology in Cambridge, where he has been ever since. He now heads the Protein and Nucleic Acid Chemistry division, which he previously co-directed with Dr Fred Sanger - twice a Nobel Laureate, now retired.

Milstein has always worked on the structure, genetics and evolution of antibody molecules. Perhaps the best known of his "pre-monoclonal" papers is that in Nature New Biology 239, 117; 1972, which demonstrated that the light chain of antibodies is first produced as a larger precursor molecule, whose extra sequence serves as a signal for the process of attachment to, and secretion through, the lymphocyte membrane, during which it is cleaved off. This was probably the first firm evidence to support the signal sequence hypothesis of Blobel and Sabatini.

In 1974, Georges Köhler, then a 27-yearold West German at the Basel Institute of Immunology, obtained an EMBO grant to work at Cambridge with Milstein. His chief interest was the development of antibodyproducing cell lines to allow the analysis of the rates of mutation of their antibody genes and so to study the role of somatic mutation in the generation of antibody diversity. It was not by design that monoclonal technology emerged from this research, and the relative contributions of Kohler and Milstein to the discovery is a matter of controversy. The pair have shared some minor prizes, but both the Wolf prize (an Israeli's answer to Nobel) in medicine and the Sloan prize of the General Motors Cancer Research Foundation went to Milstein alone. The Nobel committee has obviously decided that Köhler played a substantial part in the discovery. Köhler returned to the Basel institute in 1976, becoming a permanent member in 1980; he has maintained his interest in the mechanism of antibody diversity. Next March he becomes co-director of the Max Planck Institute of Immunology in Freiburg.

When Köhler returned to Basel it was still under the direction of Niels Jerne, the founding director of the Basel Institute of Immunology, from which he retired in 1980. Jerne was born in Denmark in 1911, started life as a student of physics but soon switched to medicine. From 1943 to 1956 he was at the Danish State Serum Institute and there began his studies on antibodies. $\mathrm{He}$ had spells of a few years in Geneva (for the university and World Health Organization), as a visitor at the California Institute of Technology, at the University of Pittsburgh and as director of the Paul Ehrlich Institute in Frankfurt. Technically, his most important paper of that period is probably the description of the plaqueforming assay (Science 140, 405; 1963), a test that allows the quantitation of antibody-producing cells of a particular specificity among a mixed population.

In 1969 when Hoffmann-La Roche founded the Basel Institute of Immunology, Jerne became its first director. During his tenure as director, he became ever more widely acknowledged as the father of several influential, if not always correct, ideas in immunology. In particular he was involved in the theory of antibody selection by antigen - the doctrine that antigens do not instruct the immune system to manufacture new antibodies, but rather select the relevant antibody-producing cell from a pre-existing pool.

Jerne's network theory of immunology, an outcome of his analytical approach to a subject bedevilled by murky observations and operational definitions, was at its most influential about a decade ago. It was based on the fact that antibodies can themselves serve as antigens, Jerne postulated that any antigen would set off a train of events, with each antibody acting also as an antigen and thus linking cells of the immune system in a network since their antigen-binding sites were almost certain to recognize one of the antibodies produced in the course of the response. But in spite of strong experimental evidence in support of the network theory, it remains difficult to determine whether the regulation of most immune responses is substantially controlled in this way.

This year's prizes will be thought well deserved. They will be seen as further justification of the British Medical Research Council's support of basic research at its Laboratory for Molecular Biology in Cambridge. Milstein joins Aaron Klug, Francis Crick, James Watson, Max Perutz and John Kendrew as well as Sanger (twice), whose work at Cambridge brought them a trip to Stockholm. The prizes will also no doubt be seen in certain quarters as a justification of Hoffmann-La Roche's wisdom in founding a basic research institute. But above all this year's Physiology and Medicine prize demonstrates how theory, experiment, curiosity and serendipity can produce not only great scientific insight but what is certain to turn out to be tremendous benefits to mankind.

Peter Newmark 